\title{
Optimization-Based TOPSIS Method with Incomplete Weight Information under Nested Probabilistic-Numerical Linguistic Environment
}

\author{
Yan Deng ${ }^{1}{ }^{1}$ Xinxin Wang, ${ }^{2}$ and Chao Min $\mathbb{D}^{1}$ \\ ${ }^{1}$ School of Science, Institute for Artificial Intelligence, Southwest Petroleum University, Chengdu, China \\ ${ }^{2}$ Business School, Sichuan University, Chengdu, China \\ Correspondence should be addressed to Yan Deng; dengyan@stu.swpu.edu.cn
}

Received 18 May 2020; Accepted 22 June 2020; Published 31 July 2020

Academic Editor: Anna M. Gil-Lafuente

Copyright (c) 2020 Yan Deng et al. This is an open access article distributed under the Creative Commons Attribution License, which permits unrestricted use, distribution, and reproduction in any medium, provided the original work is properly cited.

With the development of the economic and technology, decision-making problems are more and more complex and uncertain. Experts have difficulty in expressing evaluation information because of different research background and insufficient cognition of knowledge structure. Attribute weight information has been often incomplete in decision-making problems. Considering that nested probabilistic-numerical linguistic term sets (NPNLTSs) are flexible to express qualitative and quantitative information, in this paper, we firstly establish an optimization model based on distance measures to obtain the attribute weight. Combined with a classical decision-making method, an optimization-based TOPSIS method with NPNLTSs is proposed to deal with complex decision-making problems. After that, a case study about the river health assessment is given to show the effectiveness and practicability of the proposed method. Finally, some comparative analysis and discussion are provided from three aspects, including the impact for the results without weight optimization, the impact for the results under other uncertain environments, and the impact for the results using other decision-making methods. As a result, the proposed optimization-based TOPSIS method is effective and reliable. The optimization-based TOPSIS method proposed in this paper provides a new way to deal with uncertain and practical problems, which makes a technically sound contribution to the decision-making field.

\section{Introduction}

With the rapid development of the economic and society, the uncertainty and complexity of decision-making problems are more and more obvious $[1,2]$. In particular, uncertainty is mainly reflected in assessment of alternative, and complexity appears in the information types. At present, decision experts have preferred to express evaluation information by various linguistic models because of practicality and cognitive behavior [3]. Zadeh firstly introduced the fuzzy linguistic approach [3], and some extended linguistic models have been proposed later by scholars [4-7]. For example, hesitant fuzzy linguistic term set (HFLTS) was proposed to express indecisive linguistic information by decision experts [8], and HFLTSs allow to use multiple possible linguistic terms to describe evaluation information but cannot show the weight or possibility of the linguistic term. Later, Pang [9] proposed probabilistic linguistic term set (PLTS) which permits people to use possible linguistic term with the corresponding probability. So far, various linguistic models have been studied by researchers in many aspects, such as operational laws [10-12], distance measures $[13,14]$, and decision-making methods [15-17]. Considering the type and the structure of evaluation information, nested probabilistic-numerical linguistic term set (NPNLTS) was proposed to help decision experts express qualitative and quantitative information based on PLTS [18]. The characteristics of NPNLTSs are that the linguistic term can be ordinal variable, such as "bad", "general," and "good", and also can be nominal variable, such as "orange", "jacinth," and "red". Moreover, decision experts can express nested evaluation information with NPNLTSs, which is more flexible 
and accurate to describe uncertain and complex information. And NPNLTSs have been used to deal with multiple attribute group decision-making problems, such as project investment [18] and water resource management [19].

In this paper, we study the decision-making method with NPNLTSs under complex and uncertain environment. Under the circumstances, attribute weight has been always incomplete or vague, and it is necessary to obtain the rational attribute weight scientifically because it plays a vital role in aggregation information. Up to now, researchers have proposed various methods to deal with incomplete weight information, such as entropy for objective weights [20], analytic hierarchy process (AHP) [21, 22], minimize deviation [23], and fuzzy for subjective weights [24]. For examples, Jong [25] proposed an extended VIKOR method using incomplete criteria weights, which ranks alternatives using the aggregated scores. Song [26] provided a threereference-point decision-making method with incomplete weight information considering independent and interactive characteristics. Zhang [27] established two optimization models to minimize the deviation between each decision expert's evaluation and the group's collective evaluation on each alternative so that experts can obtain complete weight, due to that the minimize deviation method is effective and useful to get weight information and has been widely applied to decision-making problems [28-31]. Motivated by this method, an optimization model is established to calculate attribute weight under nested probabilistic-numerical linguistic environment.

In addition, the TOPSIS method is a classical decisionmaking method and has been studied in various linguistic environments and fields [32-34] because of its practicability and effectiveness. Specifically, the effects of normalization on the entropy-based TOPSIS method was proposed by Chen to normalize attributes [35]. Aiming at properly dealing with the uncertainty of the decision process, Micale [36] proposed a combined interval-valued ELECTRE TRI and TOPSIS approach for solving the storage location assignment problem. An approach of TOPSIS technique was provided to develop supplier selection with group decision-making under type-2 neutrosophic number [37]. Therefore, in this paper, we mainly study the decision-making problem with incomplete attribute information. An optimization-based TOPSIS method with NPNLTSs is proposed to deal with complex and uncertain problems and apply to a case study considering the river healthy assessment.

The contributions in this paper mainly lie in the following aspects: (1) according to incomplete attribute weight information, an optimization model with NPNLTSs is established to obtain scientific attribute weight, which is useful to solve uncertain and practical problems. (2) Combined with the TOPSIS method and NPNLTSs, an optimization-based TOPSIS method is proposed to deal with multiple attribute decision-making problems, and we apply to a case study about river healthy assessment. (3) Some comparative analysis is discussed by simulation experiments from three angles, which are the impact for the results without weight optimization, the impact for the results under other uncertain environments, and the impact for the results using other decision-making methods.

To do so, the rest of this paper is organized as follows: in Section 2, some concepts and operation of the nested probabilistic-numerical linguistic term sets are presented. Section 3 establishes an optimization model of incomplete weight information based on distance measures. In Section 4, an optimization-based TOPSIS method is proposed to deal with decision-making problems. Section 5 presents a case study about river healthy assessment and makes comparative analysis from three aspects. Section 6 ends the paper with some conclusions.

\section{Preliminaries}

Nested probabilistic-numerical linguistic term set (NPNLTS) is a useful tool to describe uncertain and complex information, especially for qualitative and nested information. In the following, we recall some concepts and operations related to NPNLTS. Firstly, the NPNLTS and the normalized NPNLTS were defined.

Definition 1 (see [18]). Let NPN $=\{\mathrm{OL}(p)\{\operatorname{IL}(v)\}\}$ be a NPNLTS, which consists of an outer-layer probabilistic linguistic term set (OPLTS) $\mathrm{OL}(p)$ and an inner-layer numerical linguistic term set (INLTS) IL $(v)$, i.e.,

$$
\begin{aligned}
\mathrm{OL}(p) & =\left\{\mathrm{OL}^{(k)}\left(p^{(k)}\right) \mid \mathrm{OL}^{(k)} \in \mathrm{OS}, \quad p^{(k)} \geq 0, k=1,2, \ldots, \# \mathrm{OL}(p), \sum_{k=1}^{\# \mathrm{OL}(p)} p^{(k)} \leq 1\right\}, \\
\mathrm{IL}(v) & =\left\{\mathrm{IL}_{(k)}^{(l)}\left(v_{(k)}^{(l)}\right) \mid \mathrm{IL}_{(k)}^{(l)} \in \mathrm{IS}, \quad v_{(k)}^{(l)} \geq 0, k=1,2, \ldots, \# \mathrm{OL}(p), l=1,2, \ldots, \# \mathrm{IL}(v)\right\},
\end{aligned}
$$

where OS and IS are an outer-layer linguistic term set (OLTS) and an inner-layer linguistic term set (ILTS), respectively. $\mathrm{OL}^{(k)}\left(p^{(k)}\right)$ is the $k$-th outer-layer linguistic term element (OLTE) in the OLTS associated with the probability $p^{(k)}$, and \#OL $(p)$ is the number of the linguistic term elements in $\mathrm{OL}(p) \cdot \operatorname{IL}_{(k)}^{(l)}\left(v_{(k)}^{(l)}\right)$ is the $l$-th inner-layer linguistic term element (ILTE) in the ILTS associated with the value $v_{(k)}^{(l)}$ under $k$-th OLTE, and \#IL $(v)$ is the number of the linguistic term elements in IL $(v)$.

When the NPNLTS NPN $=\{\mathrm{OL}(p)\{\mathrm{IL}(v)\}\}$ satisfies the following conditions: $(1) \# \mathrm{OL}(p)$ equals the number of elements in OS; (2) \#IL $(v)$ equals the number of elements in 
IS; (3) $\sum_{k=1}^{\# \mathrm{OL}(p)} p^{(k)}=1$; (4) $0 \leq v_{(k)}^{(l)} \leq 1$. Then, the NPNLTS is the normalized NPNLTS (N-NPNLTS).

Score function and comparison laws of the linguistic term sets are two of the basic operations to calculate conveniently for further study. Next, the score function and comparison laws of NPNLTSs were defined based on the definition of NPNLTS.

Definition 2 (see [18]). Let NPN $=\{\mathrm{OL}(p)\{\operatorname{IL}(v)\}\}$ be a NPNLTS, where $\mathrm{OL}(p)=\left\{\mathrm{OL}^{(k)}\left(p^{(k)}\right) \mid k=1, \ldots, \quad \# \mathrm{OL}\right.$ $(p)\}$ and $r^{(k)}$ be the subscript of $\mathrm{OL}^{(k)}$ in the OLTS, while $\operatorname{IL}(v)=\left\{\operatorname{IL}_{(k)}^{(l)}\left(v_{(k)}^{(l)}\right) \mid l=1, \ldots, \# \operatorname{IL}(v)\right\}$ and $t_{(k)}^{(l)}$ be the subscript of IL $(k)$ in ILTS under $k$-th OLTE. Then, the outerlayer's score of $\mathrm{OL}(p)$ is

$$
\mathrm{OE}(\mathrm{OL}(p))=s_{\bar{\alpha}},
$$

where $\bar{\alpha}=\sum_{k=1}^{\# \mathrm{OL}(p)} r^{(k)} p^{(k)} / \sum_{k=1}^{\# \mathrm{OL}(p)} p^{(k)}$, and the interlayer's score of $\operatorname{IL}(v)$ is

$$
\operatorname{IE}(\operatorname{IL}(v))=\left\{\bar{v}_{(k)}^{(l)} \mid k=1, \ldots, \# \mathrm{OL}(p), l=1,2, \ldots, \# \operatorname{IL}(v)\right\},
$$

where $\quad \bar{v}_{(k)}^{(l)}=(\lceil\bar{\alpha}\rceil-\bar{\alpha}) \times \mathrm{IL}_{(\lfloor\bar{\alpha}\rfloor)}\left(v_{(k)}^{(l)}\right)+(\bar{\alpha}-\lfloor\bar{\alpha}\rfloor) \times \mathrm{IL}_{(\lceil\bar{\alpha}])}$ $\left(v_{(k)}^{(l)}\right),\lceil\bar{\alpha}\rceil$ means the smallest integer greater than $\bar{\alpha}$, and $\lfloor\bar{\alpha}\rfloor$ means the greatest integer less than $\bar{\alpha}$. Then, the whole score of NPN is

$$
F(\mathrm{NPN})=\frac{\sum_{l=1}^{\# \mathrm{IL}(v)}\left(\bar{v}_{(k)}^{(l)}\right)}{\# \operatorname{IL}(v)} .
$$

The comparison laws of any two NPNLTSs, $\mathrm{NPN}_{1}$ and $\mathrm{NPN}_{2}$, can be presented as follows [18]:

(1) if $F\left(\mathrm{NPN}_{1}\right)>F\left(\mathrm{NPN}_{2}\right)$, then $\mathrm{NPN}_{1}$ is superior to $\mathrm{NPN}_{2}$, denoted by $\mathrm{NPN}_{1}>\mathrm{NPN}_{2}$

(2) if $F\left(\mathrm{NPN}_{1}\right)<F\left(\mathrm{NPN}_{2}\right)$, then $\mathrm{NPN}_{1}$ is inferior to $\mathrm{NPN}_{2}$, denoted by $\mathrm{NPN}_{1}<\mathrm{NPN}_{2}$

(3) if $F\left(\mathrm{NPN}_{1}\right)=F\left(\mathrm{NPN}_{2}\right)$, then further compared with deviation function. The deviation degree of a NPNLTS is

$$
\sigma(\mathrm{NPN})=\left(\frac{\sum_{l=1}^{\# \mathrm{IL}(v)}\left(v^{(l)}-F(\mathrm{NPN})\right)^{2}}{\# \mathrm{IL}(v)}\right)^{(1 / 2)} .
$$

Therefore, if $\sigma\left(\mathrm{NPN}_{1}\right)>\sigma\left(\mathrm{NPN}_{2}\right)$, then $\mathrm{NPN}_{1}<\mathrm{NPN}_{2}$; if $\sigma\left(\mathrm{NPN}_{1}\right)<\sigma\left(\mathrm{NPN}_{2}\right)$, then $\mathrm{NPN}_{1}>\mathrm{NPN}_{2}$, and if $\sigma\left(\mathrm{NPN}_{1}\right)=\sigma\left(\mathrm{NPN}_{2}\right)$, then $\mathrm{NPN}_{1}$ is indifferent to $\mathrm{NPN}_{2}$, denoted by $\mathrm{NPN}_{1} \sim \mathrm{NPN}_{2}$.

Moreover, two basic operations of INLTSs and OPLTSs in the NPNLTSs are introduced: addition and multiplication, defined as follows.

Definition 3 (see [18]). Let $\mathrm{NPN}_{1}=\left\{\left\{\mathrm{OL}_{1}^{(k)}\left(p_{1}^{(k)}\right) \mid k=\right.\right.$ $\left.\left.1,2, \ldots, \# \mathrm{OL}_{1}(p)\right\}\left\{\mathrm{IL}_{1}^{(l)}\left(v_{1}^{(l)}\right) \mid l=1,2, \ldots, \# \mathrm{IL}_{1}(v)\right\}\right\}$ and $\mathrm{NPN}_{2}=\left\{\left\{\mathrm{OL}_{2}^{(k)}\left(p_{2}^{(k)}\right) \mid k=1,2, \ldots, \# \mathrm{OL}_{2}(p)\right\}\left\{\mathrm{IL}_{2}^{(l)}\left(v_{2}^{(l)}\right) \mid\right.\right.$ $\left.\left.l=1,2, \ldots, \# \mathrm{IL}_{2}(v)\right\}\right\}$ be two NPNLTSs. For $\lambda_{1}, \lambda_{2}>0$,

$$
\begin{gathered}
\mathrm{OL}_{1}(p) \oplus \mathrm{OL}_{2}(p)=\cup_{\mathrm{OL}_{1}^{(k)} \in \mathrm{OL}_{1}(p), \mathrm{OL}_{2}^{(k)} \in \mathrm{OL}_{2}(p)}\left\{\mathrm{OL}_{1}^{(k)}\left(p_{1}^{(k)}\right) \oplus \mathrm{OL}_{2}^{(k)}\left(p_{2}^{(k)}\right)\right\}, \\
\lambda_{1} \mathrm{IL}_{1}(v) \oplus \lambda_{2} \mathrm{IL}_{2}(v)=\cup_{\mathrm{IL}_{1}^{(l)} \in \mathrm{IL}_{1}(v), \mathrm{IL}_{2}^{(l)} \in \mathrm{IL}_{2}(v)}\left\{\left(\lambda_{1} \mathrm{IL}_{1}^{(l)}\left(v_{1}^{(l)}\right) \oplus \lambda_{2} \mathrm{IL}_{2}^{(l)}\left(v_{2}^{(l)}\right)\right)\right\}, \\
\mathrm{OL}_{1}(p) \otimes \mathrm{OL}_{2}(p)=\cup_{\mathrm{OL}_{1}^{(k)} \in \mathrm{OL}_{1}(p), \mathrm{OL}_{2}^{(k)} \in \mathrm{OL}_{2}(p)}\left\{\mathrm{OL}_{1}^{(k)}\left(p_{1}^{(k)}\right) \otimes \mathrm{OL}_{2}^{(k)}\left(p_{2}^{(k)}\right)\right\}, \\
\lambda_{1} \mathrm{IL}_{1}(v) \otimes \lambda_{2} \mathrm{IL}_{2}(v)=\cup_{\mathrm{IL}_{1}^{(l)} \in \mathrm{IL}_{1}(v), \mathrm{IL}_{2}^{(l)} \in \mathrm{IL}_{2}(v)}\left\{\left(\left(\mathrm{IL}_{1}^{(l)}\left(v_{1}^{(l)}\right)\right)^{\lambda_{1}} \otimes\left(\mathrm{IL}_{2}^{(l)}\left(v_{2}^{(l)}\right)\right)^{\lambda_{2}}\right)\right\},
\end{gathered}
$$

where $\mathrm{OL}_{1}^{(k)}$ and $\mathrm{OL}_{2}^{(k)}$ are the $k$-th linguistic terms and $p_{1}^{(k)}$ and $p_{2}^{(k)}$ are the probabilities of the $k$-th linguistic terms in $\mathrm{OL}_{1}^{(k)}$ and $\mathrm{OL}_{2}^{(k)}$, respectively. $\mathrm{IL}_{1}^{(l)}$ and $\mathrm{IL}_{2}^{(l)}$ are the $l$-th linguistic terms and $v_{1}^{(l)}$ and $v_{2}^{(l)}$ are the values of the $l$-th linguistic terms in $\mathrm{IL}_{1}(v)$ and $\mathrm{IL}_{2}(v)$, respectively.

\section{Optimization Model of Incomplete Weight Information}

In this section, we introduce incomplete weight information about attributes in decision-making problems and further establish an optimization model to calculate the weights.

As for a multiple attributes group decision-making problem under the nested probabilistic-numerical linguistic environment, let $A=\left\{A_{1}, A_{2}, \ldots, A_{m}\right\}$ be a set of alternatives, $C=\left\{C_{1}, C_{2}, \ldots, C_{n}\right\}$ be a set of attributes, and $\omega=$ $\left(\omega_{1}, \omega_{2}, \ldots, \omega_{n}\right)^{T}$ be the corresponding attribute vector, which satisfies $\sum_{j=1}^{n} \omega_{j}=1$ and $\omega_{j} \geq 0, j=1,2, \ldots, n . E=$ $\left\{E_{1}, E_{2}, \ldots, E_{k}\right\}$ is a set of experts, and $w=\left(w_{1}\right.$, $\left.w_{2}, \ldots, w_{k}\right)^{T}$ is the associated weight vectors over experts, with $w_{q} \geq 0$ and $\sum_{q=1}^{k} w_{q}=1$. Let OS $=\left\{s_{0}, s_{1}, \ldots, s_{\tau}\right\}$ be the OLTS, IS $=\left\{n_{0}, n_{1}, \ldots, n_{\zeta}\right\}$ be the ILTS, and $\mathrm{NPN}^{q}=$ $\left(\mathrm{NPN}_{i j}^{q}\right)_{m \times n}(q=1,2, \ldots, k)$ be the decision matrix given by the expert $E_{q} \in E$, where $\mathrm{NPN}_{i j}^{q}$ represents the evaluation information for alternative $A_{i} \in A$ with respect to the attribute $C_{j} \in C$ :

$$
\mathrm{NPN}^{q}=\left(\begin{array}{cccc}
\mathrm{NPN}_{11}^{q} & \mathrm{NPN}_{12}^{q} & \cdots & \mathrm{NPN}_{1 n}^{q} \\
\mathrm{NPN}_{21}^{q} & \mathrm{NPN}_{22}^{q} & \cdots & \mathrm{NPN}_{2 n}^{q} \\
\vdots & \vdots & \ddots & \vdots \\
\mathrm{NPN}_{m 1}^{q} & \mathrm{NPN}_{m 2}^{q} & \cdots & \mathrm{NPN}_{m n}^{q}
\end{array}\right)
$$

Since the complex and uncertain environment, experts give the incomplete weight information for attributes. Up to 
now, the incomplete weight has been mainly divided into six cases [38]: (1) $\omega_{i} \geq \omega_{j}$; (2) $\omega_{i}-\omega_{j} \geq \alpha_{i}$; (3) $\omega_{i} \geq \beta_{i} \omega_{j}$; (4) $\gamma_{i}+\varepsilon_{i} \geq \omega_{i} \geq \gamma_{i}$; (5) $\left(\theta_{i}+\varepsilon_{i}\right) \omega_{j} \geq \theta_{i} \omega_{j}$ or $\theta_{i} \leq \omega_{i} / \omega_{j} \geq\left(\theta_{i}+\varepsilon_{i}\right)$, $\omega_{j} \neq 0$; (6) $\omega_{i}-\omega_{j} \geq \omega_{k}-\omega_{l}, j \neq k \neq l$, where $\alpha_{i}, \beta_{i}, \gamma_{i}, \theta_{i}$, and $\varepsilon_{i}$ are nonnegative constants.

As for a finite number of alternatives, the essence of the multiattribute decision-making is to compare and rank the comprehensive attribute values of alternatives. Considering the attribute values of alternatives with respect to attribute $C_{j}$, if the difference is smaller, then the effect of the attribute $C_{j}$ on the decision results is smaller. On the contrary, if the difference is larger, it shows that the attribute $C_{j}$ plays an important role during decision-making process. From the perspective of alternatives' ranking, the attribute of the alternative with greater deviation should be given greater weight. In particular, if the attribute values of alternatives are the same, then the attribute $C_{j}$ do not work on the alternatives' ranking and then let the attribute weight be 0 . As we can see, this way can evaluate the weight of attributes objectively.

For any attribute $C_{j}$ in the decision matrix $\mathrm{NPN}^{q}=$ $\left(\mathrm{NPN}_{i j}^{q}\right)_{m \times n}(q=1,2, \ldots, k)$, distance measure is used to represent the deviation $D_{i}(\omega)$ between alternative $A_{i}$ and alternative $A_{k}$. According to the generalized weighted distance measure with nested probabilistic-numerical linguistic information [19], the deviation $D_{i}(\omega)$ is defined as follows.

Definition 4. Let NPN $=\left(\mathrm{NPN}_{i j}\right)_{m \times n}$ be the decision matrix with nested probabilistic-numerical linguistic information. $\omega=\left(\omega_{1}, \omega_{2}, \ldots, \omega_{n}\right)^{T}$ is the weight vector of attributes, where $0 \leq \omega_{j} \leq 1$ and $\sum_{j=1}^{n} \omega_{j}=1$, and the deviation $D_{i}(\omega)$ between alternative $A_{i}$ and alternative $A_{k}$ based on the generalized weighted distance measure is defined as

$$
\begin{aligned}
D_{i}(\omega) & =\sum_{k=1}^{m} \sum_{j=1}^{n} d\left(\mathrm{NPN}_{i j}, \mathrm{NPN}_{k j}\right) \\
& \left.=\sum_{k=1}^{m} \sum_{j=1}^{n}\left(\frac{\omega_{j}}{\# \mathrm{OL} \times \# \mathrm{IL}} \sum_{k=1}^{\# \mathrm{OL}} \sum_{l=1}^{\# \mathrm{IL}}\left(\frac{\left(\left(\left|\mathrm{OL}_{i j}^{(k)}-\mathrm{OL}_{k j}^{(k)}\right| / \tau+1\right)+\left|p_{i j}^{(k)}-p_{k j}^{(k)}\right|+\left(\left|\mathrm{IL}_{i j}^{(l)}-\mathrm{IL}_{k j}^{(l)}\right| / \varsigma+1\right)+\left|v_{i j}^{(l)}-v_{k j}^{(l)}\right|\right)}{4}\right)\right)^{\lambda}\right)
\end{aligned}
$$

where $\lambda>0$, \#OL is the number of the linguistic term elements in OLTS, and \#IL is the number of the linguistic term elements in ILTS. In particular, when $\lambda=1$ and $\lambda=2$, the generalized weighted distance measure reduces to Hamming weighted distance measure and Euclid weighted distance measure, respectively.
For all attributes $C_{j}(j=1,2, \ldots, n), D(\omega)$ denotes the sum of deviation between alternative $A_{i}$ and other alternatives. In order to determine the weight vector $\omega$, we need to maximize the $D(\omega)$. Therefore, the objective function is as follows:

$\max D(\omega)$

$$
\begin{aligned}
& =\sum_{i=1}^{m} D_{i}(\omega)=\sum_{i=1}^{m} \sum_{k=1}^{m} \sum_{j=1}^{n}\left(\frac{\omega_{j}}{\# O L \times \# I L} \sum_{k=1}^{\# O L} \sum_{l=1}^{\# I L}\right. \\
& \left.\left(\frac{\left(\left(\left|\mathrm{OL}_{i j}^{(k)}-\mathrm{OL}_{k j}^{(k)}\right| / \tau+1\right)+\left|p_{i j}^{(k)}-p_{k j}^{(k)}\right|+\left(\left|\mathrm{IL}_{i j}^{(l)}-\mathrm{IL}_{k j}^{(l)}\right| / \varsigma+1\right)+\left|v_{i j}^{(l)}-v_{k j}^{(l)}\right|\right)}{4}\right)^{\lambda}\right)^{1 / \lambda} .
\end{aligned}
$$

And the optimization model is established to obtain the weight vector of attributes:

Model I:

$$
\begin{array}{ll}
\max & D(\omega) \\
\text { s.t. } & \sum_{j=1}^{n} \omega_{j}=1, \omega_{j} \geq 0, j=1,2, \ldots, n .
\end{array}
$$

\section{Optimization-Based TOPSIS Method}

In this section, an optimization-based TOPSIS method with the nested probabilistic-numerical linguistic information is proposed, and the corresponding algorithm is presented. 
4.1. The Extended TOPSIS Method. TOPSIS method is a classical method, and it has been widely applied to many fields. Considering incomplete weight information of attributes, we propose an extended TOPSIS method with the nested probabilistic-numerical linguistic information. Firstly, we define some concepts related to the extended TOPSIS method.

Definition 5. Let NPN $=\left(\mathrm{NPN}_{i j}\right)_{m \times n}=\left(\mathrm{OL}_{i j}(p)\{\mathrm{IL}(v)\}\right)_{m \times n}$ be the decision matrix with the nested probabilistic-numerical linguistic information. For the alternative $A_{i}(i=1,2, \ldots, m), \mathrm{NPN}_{i}=\left(\mathrm{NPN}_{i 1}, \mathrm{NPN}_{i 2}, \ldots, \mathrm{NPN}_{i n}\right)$ is the attribute vector. $\mathrm{NPN}^{+}=\left(\mathrm{NPN}_{1}^{+}, \mathrm{NPN}_{2}^{+}, \ldots, \mathrm{NPN}_{n}^{+}\right)$is the positive ideal solution (PIS) of the alternative, where

$$
\begin{aligned}
\mathrm{NPN}_{j}^{+} & =\left\{\left(\mathrm{OL}_{j}^{(k)}\{\mathrm{IL}\}\right)^{+} \mid \quad k=1,2, \ldots, \# \mathrm{OL}_{i j}\right\}, \\
\left(\mathrm{OL}_{j}^{(k)}\{\mathrm{IL}\}\right)^{+} & =s^{(k)}\left(\max _{i}\left(p_{i j}^{(k)}\right)\right)\{\mathrm{IL}\}, \quad j=1,2, \ldots, n, \\
\mathrm{NPN}^{-} & =\left(\mathrm{NPN}_{1}^{-}, \mathrm{NPN}_{2}^{-}, \ldots, \mathrm{NPN}_{n}^{-}\right)
\end{aligned}
$$

is the negative ideal solution (NIS) of the alternative, where

$$
\begin{aligned}
\mathrm{NPN}_{j}^{-} & =\left\{\left(\mathrm{OL}_{j}^{(k)}\{\mathrm{IL}\}\right)^{-} \mid \quad k=1,2, \ldots, \# \mathrm{OL}_{i j}\right\}, \\
\left(\mathrm{OL}_{j}^{(k)}\{\mathrm{IL}\}\right)^{-} & =s^{(k)}\left(\min _{i}\left(p_{i j}^{(k)}\right)\right)\{\mathrm{IL}\}, \quad j=1,2, \ldots, n .
\end{aligned}
$$

According to the decision matrix $\mathrm{NPN}=\left(\mathrm{NPN}_{i j}\right)_{m \times n}$, the PIS and the NIS are

$$
\begin{aligned}
\mathrm{NPN}^{+} & =\left(\mathrm{NPN}_{1}^{+}, \mathrm{NPN}_{2}^{+}, \ldots, \mathrm{NPN}_{n}^{+}\right), \\
\mathrm{NPN}^{-} & =\left(\mathrm{NPN}_{1}^{-}, \mathrm{NPN}_{2}^{-}, \ldots, \mathrm{NPN}_{n}^{-}\right),
\end{aligned}
$$

respectively. The deviation between each alternative and the PIS is defined as follows:

$$
d\left(A_{i}, \mathrm{NPN}^{+}\right)=\omega_{j} d\left(\mathrm{NPN}_{i j}, \mathrm{NPN}_{j}^{+}\right)=\omega_{j}\left(\frac{1}{\# \mathrm{OL}_{i j}} \sum_{k=1}^{\# \mathrm{OL}_{i j}}\left(\frac{\left(\left(\left|\mathrm{OL}_{i j}^{(k)}-\mathrm{OL}_{i j}^{+}\right| / \tau+1\right)+\left|p_{i j}^{(k)}-p_{i j}^{+}\right|\right)}{2}\right)^{2}\right)^{1 / 2},
$$

and the deviation between each alternative and the NIS is

$$
d\left(A_{i}, \mathrm{NPN}^{-}\right)=\omega_{j} d\left(\mathrm{NPN}_{i j}, \mathrm{NPN}_{j}^{-}\right)=\omega_{j}\left(\frac{1}{\# \mathrm{OL}_{i j}} \sum_{k=1}^{\# \mathrm{OL}_{i j}}\left(\frac{\left(\left(\left|\mathrm{OL}_{i j}^{(k)}-\mathrm{OL}_{i j}^{-}\right| / \tau+1\right)+\left|p_{i j}^{(k)}-p_{i j}^{-}\right|\right)}{2}\right)^{2}\right)^{1 / 2} .
$$

The smaller the deviation $d\left(A_{i}, \mathrm{NPN}^{+}\right)$, the better the alternative $A_{i}$, and the larger the deviation $d\left(A_{i}, \mathrm{NPN}^{-}\right)$, the better the alternative $A_{i}$. Let

$$
d_{\min }\left(A_{i}, \mathrm{NPN}^{+}\right)=\min _{1 \leq i \leq m} d\left(A_{i}, \mathrm{NPN}^{+}\right)
$$

be the smallest deviation between the alternative $A_{i}$ and the PIS,

$$
d_{\max }\left(A_{i}, \mathrm{NPN}^{-}\right)=\max _{1 \leq i \leq m} d\left(A_{i}, \mathrm{NPN}^{-}\right),
$$

be the largest deviation between the alternative $A_{i}$ and the NIS. Motivated by closeness coefficient [39], the inner weight of the alternative is

$$
\varepsilon_{i}\left(A_{i}\right)=\frac{\left(\left(d\left(A_{i}, \mathrm{NPN}^{-}\right) / d_{\max }\left(A_{i}, \mathrm{NPN}^{-}\right)\right)+\left(d\left(A_{i}, \mathrm{NPN}^{+}\right) / d_{\min }\left(A_{i}, \mathrm{NPN}^{+}\right)\right)\right)}{\sum_{i=1}^{m}\left(\left(d\left(A_{i}, \mathrm{NPN}^{-}\right) / d_{\max }\left(A_{i}, \mathrm{NPN}^{-}\right)\right)+\left(d\left(A_{i}, \mathrm{NPN}^{+}\right) / d_{\min }\left(A_{i}, \mathrm{NPN}^{+}\right)\right)\right)}
$$

It is noted that the inner weight is a vector, that is, $\varepsilon_{i}=\left(\varepsilon_{i 0}, \varepsilon_{i 1}, \ldots, \varepsilon_{i \tau}\right)^{T}$. And the inner-layer score $\mathrm{IZ}_{i}$ is expressed as

$$
\begin{aligned}
\mathrm{IZ}_{i} & =\varepsilon_{i 0} \mathrm{IL}_{i 1} \oplus \varepsilon_{i 1} \mathrm{IL}_{i 2} \oplus \cdots \oplus \varepsilon_{i \tau} \mathrm{IL}_{i n} \\
& =\cup_{\mathrm{IL}_{i 1}^{(l)} \in \mathrm{IL}_{i 1}(v)}\left\{\varepsilon_{i 0} \mathrm{IL}_{i 1}^{(l)}\left(v_{i 1}^{(l)}\right)\right\} \oplus \mathrm{UL}_{\mathrm{IL}_{i 2}^{(l)} \in \mathrm{IL}_{i 2}(v)}\left\{\varepsilon_{i 1} \mathrm{IL}_{i 2}^{(l)}\left(v_{i 2}^{(l)}\right)\right\} \oplus \cdots \oplus \mathrm{U}_{\mathrm{IL}_{i n}^{(l)} \in \mathrm{IL} i n(v)}\left\{\varepsilon_{i \tau} \mathrm{IL}_{i n}^{(l)}\left(v_{i n}^{(l)}\right)\right\},
\end{aligned}
$$


where $i=1,2, \ldots, m$.

According to Definition 2, the whole score $F\left(\mathrm{NPN}_{i}\right)$ of each alternative $A_{i}$ can be obtained with the inner weight $\varepsilon_{i}=\left(\varepsilon_{i 0}, \varepsilon_{i 1}, \ldots, \varepsilon_{i \tau}\right)^{T}$. Hence, we can rank the alternatives and select the best one. In particular, the comparison rule between the alternative $A_{i}$ and the alternative $A_{r}(i, r=$ $1,2, \ldots, m ; i \neq r)$ is that

(1) If $F\left(\mathrm{NPN}_{i}\right)>F\left(\mathrm{NPN}_{r}\right)$, then $A_{i}>A_{r}$

(2) If $F\left(\mathrm{NPN}_{i}\right)<F\left(\mathrm{NPN}_{r}\right)$, then $A_{i}<A_{r}$

(3) If $F\left(\mathrm{NPN}_{i}\right)=F\left(\mathrm{NPN}_{r}\right)$, further compare $\sigma\left(\mathrm{NPN}_{i}\right)$ and $\sigma\left(\mathrm{NPN}_{r}\right)$ :

(a) $\sigma\left(\mathrm{NPN}_{i}\right)>\sigma\left(\mathrm{NPN}_{r}\right)$, then $A_{i}<A_{r}$

(b) $\sigma\left(\mathrm{NPN}_{i}\right)<\sigma\left(\mathrm{NPN}_{r}\right)$, then $A_{i}>A_{r}$

(c) $\sigma\left(\mathrm{NPN}_{i}\right)=\sigma\left(\mathrm{NPN}_{r}\right)$, then $A_{i} \sim A_{r}$

4.2. The Procedure Based on Incomplete Weight Information. In order to deal with a multiattribute group decision-making problem under the nested probabilistic-numerical linguistic environment, the extended TOPSIS method with incomplete weight information is divided into four parts: (1) preparation part. Analyze the decision-making problem, and determine a set of alternatives, attributes, and experts. (2) Optimization part. Optimize attribute weight with incomplete information by Model I. (3) Evaluation part. Construct the decision matrix with NPNLTSs by experts and calculate the inner weight. (4) Decision part. Calculate the whole scores of alternatives and select the best one. In the following, we propose the algorithm of the extended TOPSIS method with incomplete weight information (Algorithm 1).

In order to better understand the procedure, Figure 1 shows the flowchart of the algorithm in decision-making with NPNLTSs.

\section{A Case Study}

In this Section, a multiple attribute group decision-making problem is considered about the river health assessment. The optimization-based TOPSIS method is used to deal with the problem, and we further make some comparative analysis considering three factors.

5.1. Problem Description. River health assessment is based on the connotation analysis, in view of the river natural, ecological, and social service functions. The connotation of the river health is that under the utilization and protection coordination of human, natural rivers, ecological function, and social service function relatively balanced the state of play, the river can realize the normal water, basic material, and energy circulation and good function, including to maintain a certain level of ecological environment and social service function and meet the demand of the sustainable development of human society, eventually form human balance development and protection of rivers of virtuous circle. According to the basic characteristics of the river and the individual characteristics, river health assessment sets up the river health evaluation system by the commonness and individuality indexes and puts forward the overall evaluation method from river to river.

River health is supposed to include the natural health of the river and the good ecological environment and social service. However, in the current social and economic background in China, several river basins are densely populated and highly developed, and it is difficult to realize the natural, ecological, and social service functions of rivers. Therefore, the river health should provide relatively good ecological environment and the social service function, and meet the needs of sustainable development of human society, the corresponding period, namely, in keeping the river natural, ecological, and social service function of a state of equilibrium. At present, some factors are popular to be considered for evaluating the river health as follows:

Monitoring status assessment of the river. The scope of monitoring is very broad, including regular surface and groundwater monitoring, process monitoring, and emergency incident monitoring. Monitoring status assessment can provide data for environmental management and provide a basis for water quality assessment of the river.

The evaluation of sustainable use of water resources. Sustainable utilization of water resources is the principle to ensure the sustainable development of human society, economy, and living environment. Life support systems and ecosystems on earth must not be compromised in the development and utilization of water resources.

The impact assessment of the hydraulic engineering. It refers to the analysis, prediction, and evaluation of the environmental quality changes caused by the construction of water conservancy projects. The scope depends on the scale, characteristics, and geographical location of the projects.

The purpose of studying and maintaining river health is to restore the river's natural function and make it play its social function in a balanced way, so as to maintain the sustainable utilization of river's social function and guarantee the sustainable development of human economy and society. In the following, we will make the river health assessment for four rivers, which are the Yangtze River, the Yellow River, the Pearl River, and the Huai River.

5.2. Solve the Problem. According to Section 5.1, four evaluation objects are put forward, and denote as $X=\left\{x_{1}, x_{2}, x_{3}, x_{4}\right\}$, where $x_{1}, x_{2}, x_{3}, x_{4}$ are the Yangtze River, the Yellow River, the Pearl River, and the Huai River, respectively. At the same time, we consider three attributes $C=\left\{c_{1}, c_{2}, c_{3}\right\}$, where $c_{1}$ is monitoring status assessment of the river, $c_{2}$ is the evaluation of sustainable use of water resources, and $c_{3}$ is the impact assessment of the hydraulic engineering. In order to evaluate the river health comprehensively, the OLTS and the ILTS are given as follows: 
Step 1. Determine a set of alternatives $A=\left\{A_{1}, A_{2}, \ldots, A_{m}\right\}$ and a set of attributes $C=\left\{C_{1}, C_{2}, \ldots, C_{n}\right\}$ by experts according to the decision-making problem. Go to Step 2.

Step 2. Provide weight information about attributes by experts, and obtain the optimized weight vector $\omega=\left(\omega_{1}, \omega_{2}, \ldots, \omega_{n}\right)^{T}$ by Model I. Go to Step 3.

Step 3. Give the OLTS OS $=\left\{s_{\alpha} \mid \alpha=0,1, \ldots, \tau\right\}$ and the ILTS IS $=\left\{n_{\beta} \mid \beta=0,1, \ldots, \varsigma\right\}$ by experts. Go to Step 4 .

Step 4. Construct the OPLTS $\mathrm{OL}_{i j}(p)=\left\{\mathrm{OL}_{i j}^{(k)}\left(p_{i j}^{(k)}\right) \mid k=1,2, \ldots, \# \mathrm{OL}_{i j}(p)\right\}$ over the alternatives $A_{i}(i=1,2, \ldots, m)$ with respect to the attributes $C_{j}(j=1,2, \ldots, n)$, where the corresponding probability $p_{i j}^{(k)}>0$. Go to Step 5 .

Step 5. Construct the $\operatorname{INLTS~IL~}_{\alpha \beta}(v)=\left\{\operatorname{IL}_{\alpha \beta}^{(l)}\left(v_{\alpha \beta}^{(l)}\right) \mid l=0,1, \ldots, \varsigma\right\}$ based on OS $=\left\{s_{\alpha} \mid \alpha=0,1, \ldots, \tau\right\}$, where the corresponding value $v_{\alpha \beta}^{(l)}>0$. Go to Step 6 .

Step 6. Get the PIS NPN ${ }^{+}$and the NIS $\mathrm{NPN}^{-}$of the alternatives by Definition 5 . Go to Step 7.

Step 7. Calculate the deviation $d\left(A_{i}, \mathrm{NPN}^{+}\right)$between the alternative and PIS by equation (15), and the deviation $d\left(A_{i}, \mathrm{NPN}^{-}\right)$ between the alternative and NIS by equation (16). Go to Step 8 .

Step 8. Get the smallest deviation $d_{\min }\left(A_{i}, \mathrm{NPN}^{+}\right)$and the largest deviation $d_{\max }\left(A_{i}, \mathrm{NPN}^{-}\right)$. Go to Step 9.

Step 9. Calculate the inner weight $\varepsilon_{i}\left(A_{i}\right)$ of the alternative $A_{i}(i=1,2, \ldots, m)$ by equation (19). Go to Step 10.

Step 10. Calculate the inner-layer score $\mathrm{IZ}_{i}$ of the alternative $A_{i}(i=1,2, \ldots, m)$ by equation (20). Go to Step 11.

Step 11. Calculate the whole score $F\left(\mathrm{NPN}_{i}\right)$ of the alternative $A_{i}(i=1,2, \ldots, m)$ by Definition 2. Go to Step 12.

Step 12. Rank the alternatives $A_{i}(i=1,2, \ldots, m)$ by comparison rule and select the best alternative. Go to Step 13 .

Step 13. End.

Algorithm 1: The extended TOPSIS method with incomplete weight information.

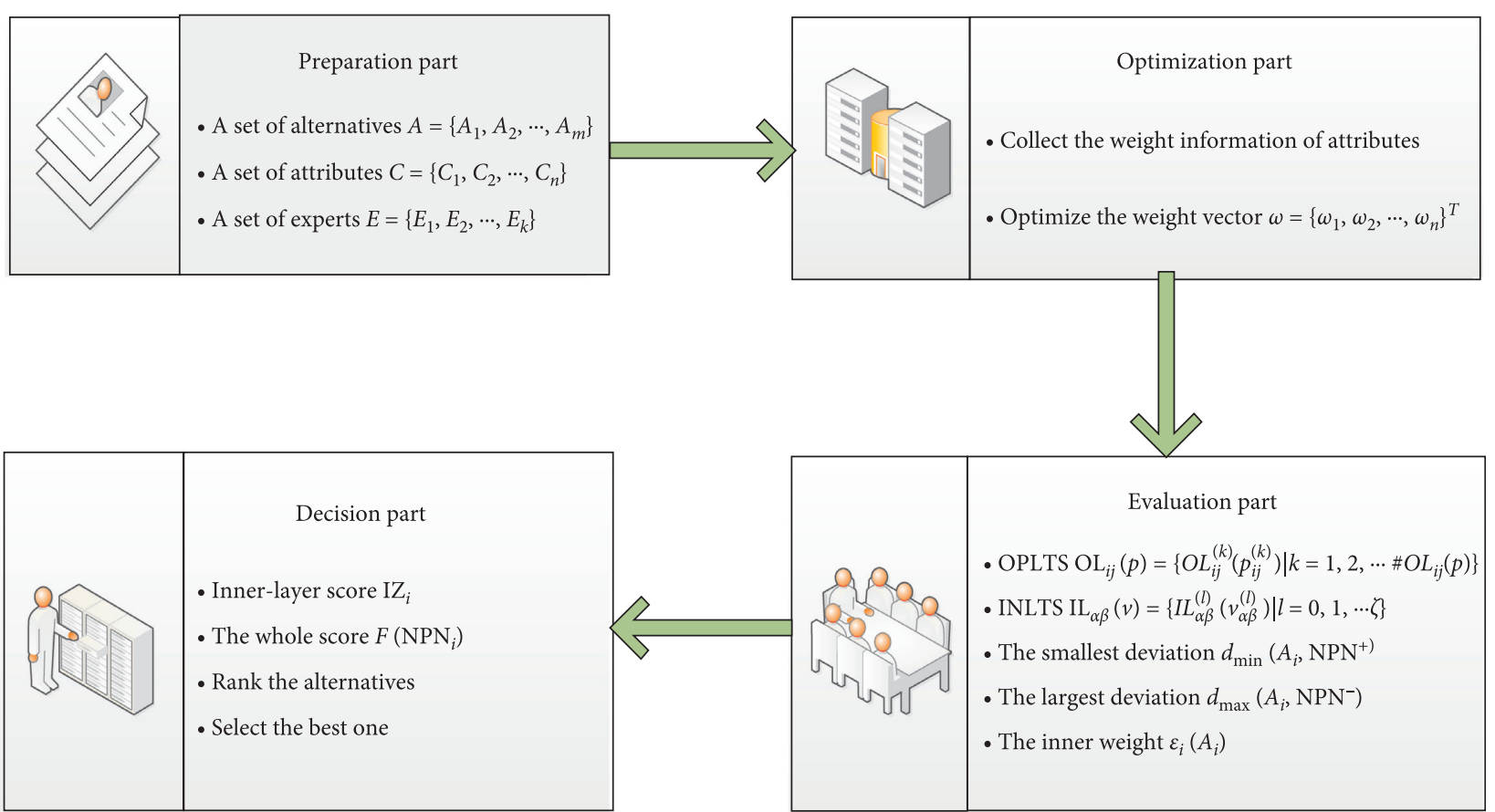

FIgURE 1: The flowchart of the optimization-based TOPSIS method algorithm with NPNLTSs.

$$
\begin{aligned}
& \text { OS }=\left\{s_{0}=\text { very bad, } s_{1}=\text { bad, } s_{2}=\text { medium, } s_{3}=\text { good, } s_{4}=\text { very good }\right\}, \\
& \text { IS }=\left\{\begin{array}{c}
n_{0}=\text { river hydrological condition, } n_{1}=\text { water environment condition, } \\
n_{2}=\text { hydrophytic habitat, } n_{3}=\text { water resources development and utilization }
\end{array}\right\} .
\end{aligned}
$$

Experts express their evaluation information with NPNLTSs. Specifically, they evaluate objects firstly with respect to the OLTS and assess each outer linguistic term in terms of the ILTS. Therefore, a nested probabilistic- 
TABLE 1: The nested probabilistic-numerical linguistic decision matrix.

\begin{tabular}{|c|c|c|c|}
\hline & $c_{1}$ & $c_{2}$ & $c_{3}$ \\
\hline$x_{1}$ & $\left.\begin{array}{c}s_{0}(0.1)\left\{n_{0}(0.2), n_{1}(0.4), n_{2}(0.4)\right\} \\
s_{1}(0.1)\left\{n_{1}(0.6), n_{2}(0.4)\right\} \\
s_{2}(0.2)\left\{n_{2}(0.2), n_{3}(0.3)\right\} \\
s_{3}(0.1)\left\{n_{3}(0.8)\right\}\end{array}\right\}$ & $\left\{\begin{array}{c}s_{0}(0.2)\left\{n_{2}(0.4)\right\}, \\
s_{1}(0.5)\left\{n_{1}(0.2), n_{2}(0.2), n_{2}(0.1)\right\} \\
s_{2}(0.1)\left\{n_{2}(0.4), n_{3}(0.6)\right\} \\
s_{3}(0.2)\left\{n_{1}(0.3), n_{2}(0.2), n_{3}(0.5)\right\}\end{array}\right\}$ & $\left\{\begin{array}{c}s_{0}(0.2)\left\{n_{0}(0.2), n_{1}(0.4), n_{2}(0.2), n_{2}(0.2)\right\} \\
s_{1}(0.2)\left\{n_{2}(0.6), n_{3}(0.4)\right\} \\
s_{2}(0.2)\left\{n_{0}(0.4), n_{1}(0.3), n_{2}(0.3)\right\} \\
s_{3}(0.2)\left\{n_{2}(0.2), n_{3}(0.8)\right\}\end{array}\right\}$ \\
\hline$x_{2}$ & $\left.\begin{array}{c}s_{0}(0.5)\left\{n_{2}(0.4)\right\} \\
s_{1}(0.2)\left\{n_{1}(0.2), n_{2}(0.3)\right\} \\
s_{2}(0.2)\left\{n_{1}(0.2), n_{2}(0.2), n_{3}(0.1)\right\} \\
s_{3}(0.1)\left\{n_{2}(0.2), n_{3}(0.8)\right\}\end{array}\right\}$ & $\left\{\begin{array}{c}s_{0}(0.2)\left\{n_{0}(0.4), n_{1}(0.4)\right\} \\
s_{1}(0.3)\left\{n_{0}(0.2), n_{1}(0.2), n_{2}(0.4)\right\} \\
s_{2}(0.3)\left\{n_{1}(0.3), n_{2}(0.2), n_{3}(0.3)\right\} \\
s_{3}(0.2)\left\{n_{0}(0.1), n_{1}(0.3), n_{2}(0.3), n_{3}(0.3)\right\}\end{array}\right\}$ & $\left\{\begin{array}{l}s_{0}(0.3)\left\{n_{1}(0.6), n_{2}(0.4)\right\} \\
s_{1}(0.2)\left\{n_{1}(0.2), n_{2}(0.3)\right\} \\
s_{2}(0.3)\left\{n_{2}(0.1), n_{3}(0.4)\right\} \\
s_{3}(0.2)\left\{n_{2}(0.2), n_{3}(0.8)\right\}\end{array}\right\}$ \\
\hline$x_{3}$ & $\left.\begin{array}{c}s_{0}(0.1)\left\{n_{0}(0.3), n_{1}(0.5)\right\} \\
s_{1}(0.2)\left\{n_{0}(0.2), n_{1}(0.4), n_{2}(0.4)\right\} \\
s_{2}(0.3)\left\{n_{2}(0.4), n_{3}(0.6)\right\} \\
s_{3}(0.4)\left\{n_{2}(0.5), n_{3}(0.5)\right\}\end{array}\right\}$ & $\left\{\begin{array}{c}s_{0}(0.4)\left\{n_{0}(0.1), n_{1}(0.2), n_{2}(0.2), n_{3}(0.5)\right\} \\
s_{1}(0.4)\left\{n_{1}(0.3), n_{2}(0.2)\right\} \\
s_{2}(0.1)\left\{n_{2}(0.2), n_{3}(0.8)\right\} \\
\\
s_{3}(0.1)\left\{n_{2}(0.4), n_{3}(0.6)\right\}\end{array}\right.$ & $\left\{\begin{array}{c}s_{0}(0.2)\left\{n_{0}(0.1), n_{1}(0.3), n_{2}(0.6)\right\}, \\
s_{1}(0.1)\left\{n_{1}(0.3), n_{2}(0.4), n_{3}(0.3)\right\}, \\
s_{2}(0.1)\left\{n_{2}(0.2), n_{3}(0.3)\right\}, \\
s_{3}(0.1)\left\{n_{2}(0.7), n_{3}(0.3)\right\}\end{array}\right\}$ \\
\hline$x_{4}$ & $\begin{array}{c}s_{0}(0.1)\left\{n_{2}(0.4)\right\} \\
s_{1}(0.1)\left\{n_{1}(0.5), n_{2}(0.5)\right\} \\
s_{2}(0.1)\left\{n_{2}(0.2), n_{3}(0.3)\right\} \\
s_{3}(0.2)\left\{n_{2}(0.4), n_{3}(0.6)\right\}\end{array}$ & $\left\{\begin{array}{c}s_{0}(0.1)\left\{n_{0}(0.1), n_{1}(0.4), n_{2}(0.5)\right\} \\
s_{1}(0.2)\left\{n_{1}(0.5), n_{2}(0.5)\right\} \\
s_{2}(0.1)\left\{n_{1}(0.2), n_{2}(0.2), n_{3}(0.1)\right\} \\
s_{3}(0.1)\left\{n_{1}(0.3), n_{2}(0.7)\right\}\end{array}\right\}$ & $\left.\begin{array}{c}s_{0}(0.2)\left\{n_{0}(0.1), n_{1}(0.2), n_{2}(0.2)\right\} \\
s_{1}(0.2)\left\{n_{1}(0.5), n_{2}(0.5)\right\} \\
s_{2}(0.3)\left\{n_{2}(0.2), n_{3}(0.3)\right\} \\
s_{3}(0.3)\left\{n_{1}(0.2), n_{2}(0.4), n_{3}(0.4)\right\}\end{array}\right\}$ \\
\hline
\end{tabular}

TABLE 2: The normalized nested probabilistic-numerical linguistic decision matrix.

\begin{tabular}{|c|c|c|c|}
\hline & $c_{1}$ & $c_{2}$ & $c_{3}$ \\
\hline$x_{1}$ & $\left.\begin{array}{c}s_{0}(0.2)\left\{n_{0}(0.2), n_{1}(0.4), n_{2}(0.4)\right\} \\
s_{1}(0.2)\left\{n_{1}(0.6), n_{2}(0.4)\right\} \\
s_{2}(0.4)\left\{n_{2}(0.4), n_{3}(0.6)\right\} \\
s_{3}(0.2)\left\{n_{3}(1)\right\}\end{array}\right\}$ & $\left.\begin{array}{c}s_{0}(0.2)\left\{n_{2}(1)\right\} \\
s_{1}(0.5)\left\{n_{1}(0.4), n_{2}(0.4), n_{3}(0.2)\right\} \\
s_{2}(0.1)\left\{n_{2}(0.4), n_{3}(0.6)\right\} \\
s_{3}(0.2)\left\{n_{1}(0.3), n_{2}(0.2), n_{3}(0.5)\right\}\end{array}\right\}$ & $\left\{\begin{array}{c}s_{0}(0.25)\left\{n_{0}(0.2), n_{1}(0.4), n_{2}(0.2), n_{3}(0.2)\right\} \\
s_{1}(0.25)\left\{n_{2}(0.6), n_{3}(0.4)\right\} \\
s_{2}(0.25)\left\{n_{0}(0.4), n_{1}(0.3), n_{2}(0.3)\right\} \\
s_{3}(0.25)\left\{n_{2}(0.2), n_{3}(0.8)\right\}\end{array}\right\}$ \\
\hline$x_{2}$ & $\left\{\begin{array}{c}s_{0}(0.5)\left\{n_{2}(1)\right\} \\
s_{1}(0.2)\left\{n_{1}(0.4), n_{2}(0.6)\right\} \\
s_{2}(0.2)\left\{n_{1}(0.4), n_{2}(0.4), n_{3}(0.2)\right\} \\
s_{3}(0.1)\left\{n_{2}(0.2), n_{3}(0.8)\right\}\end{array}\right\}$ & $\begin{array}{c}s_{0}(0.2)\left\{n_{0}(0.5), n_{1}(0.5)\right\} \\
s_{1}(0.3)\left\{n_{0}(0.25), n_{1}(0.25), n_{2}(0.5)\right\} \\
s_{2}(0.3)\left\{n_{1}(0.375), n_{2}(0.25), n_{3}(0.375)\right\} \\
s_{3}(0.2)\left\{n_{0}(0.1), n_{1}(0.3), n_{2}(0.3), n_{3}(0.3)\right\}\end{array}$ & $\left\{\begin{array}{l}s_{0}(0.3)\left\{n_{1}(0.6), n_{2}(0.4)\right\} \\
s_{1}(0.2)\left\{n_{1}(0.4), n_{2}(0.6)\right\} \\
s_{2}(0.3)\left\{n_{2}(0.2), n_{3}(0.8)\right\} \\
s_{3}(0.2)\left\{n_{2}(0.2), n_{3}(0.8)\right\}\end{array}\right\}$ \\
\hline$x_{3}$ & $\left\{\begin{array}{c}s_{0}(0.1)\left\{n_{0}(0.375), n_{1}(0.625)\right\} \\
s_{1}(0.2)\left\{n_{0}(0.2), n_{1}(0.4), n_{2}(0.4)\right\} \\
s_{2}(0.3)\left\{n_{2}(0.4), n_{3}(0.6)\right\} \\
s_{3}(0.4)\left\{n_{2}(0.5), n_{3}(0.5)\right\}\end{array}\right\}$ & $\begin{array}{c}s_{0}(0.4)\left\{n_{0}(0.1), n_{1}(0.2), n_{2}(0.2), n_{3}(0.5)\right\} \\
s_{1}(0.4)\left\{n_{1}(0.6), n_{2}(0.4)\right\} \\
s_{2}(0.1)\left\{n_{2}(0.2), n_{3}(0.8)\right\} \\
s_{3}(0.1)\left\{n_{2}(0.4), n_{3}(0.6)\right\}\end{array}$ & $\left\{\begin{array}{c}s_{0}(0.4)\left\{n_{0}(0.1), n_{1}(0.3), n_{2}(0.6)\right\} \\
s_{1}(0.2)\left\{n_{1}(0.3), n_{2}(0.4), n_{3}(0.3)\right\} \\
s_{2}(0.2)\left\{n_{2}(0.4), n_{3}(0.6)\right\} \\
s_{3}(0.2)\left\{n_{2}(0.7), n_{3}(0.3)\right\}\end{array}\right\}$ \\
\hline$x_{4}$ & $\begin{array}{c}s_{0}(0.2)\left\{n_{2}(1)\right\} \\
s_{1}(0.2)\left\{n_{1}(0.5), n_{2}(0.5)\right\} \\
s_{2}(0.2)\left\{n_{2}(0.4), n_{3}(0.6)\right\} \\
s_{3}(0.4)\left\{n_{2}(0.4), n_{3}(0.6)\right\}\end{array}$ & $\left\{\begin{array}{c}s_{0}(0.2)\left\{n_{0}(0.1), n_{1}(0.4), n_{2}(0.5)\right\}, \\
s_{1}(0.4)\left\{n_{1}(0.5), n_{2}(0.5)\right\} \\
s_{2}(0.2)\left\{n_{1}(0.4), n_{2}(0.4), n_{3}(0.2)\right\}, \\
s_{3}(0.2)\left\{n_{1}(0.3), n_{2}(0.7)\right\}\end{array}\right\}$ & $\left\{\begin{array}{c}s_{0}(0.2)\left\{n_{0}(0.2), n_{1}(0.4), n_{2}(0.4)\right\} \\
s_{1}(0.2)\left\{n_{1}(0.5), n_{2}(0.5)\right\} \\
s_{2}(0.3)\left\{n_{2}(0.4), n_{3}(0.6)\right\} \\
s_{3}(0.3)\left\{n_{1}(0.2), n_{2}(0.4), n_{3}(0.4)\right\}\end{array}\right\}$ \\
\hline
\end{tabular}

numerical linguistic decision matrix is constructed with NPNLTSs, shown as Table 1.

After normalization of attributes, the normalized nested probabilistic-numerical linguistic decision matrix can be shown in Table 2.

Due to the complexity and uncertainty of the assessment environment, experts give the incompletely weight information about the attributes as follows:

$$
\begin{aligned}
& 0.2 \leq \omega_{1} \leq 0.4,0.3 \leq \omega_{2} \leq 0.5,0.2 \leq \omega_{3} \leq 0.4,0.1 \omega_{2} \leq \omega_{3}, \\
& \omega_{j} \geq 0, \quad j=1,2,3, \sum_{j=1}^{3} \omega_{j}=1 .
\end{aligned}
$$

According to Model I, the optimization model is established to calculate the weight vector of attributes, which is shown as follows: 
TABLE 3: The positive ideal solution $\mathrm{NPN}^{+}$and the negative ideal solution $\mathrm{NPN}^{-}$.

\begin{tabular}{|c|c|c|c|}
\hline & $c_{1}$ & $c_{2}$ & $c_{3}$ \\
\hline $\mathrm{NPN}^{+}$ & $\begin{array}{c}s_{0}(0.1)\left\{n_{0}(0.375), n_{1}(0.625)\right\} \\
s_{1}(0.2)\left\{n_{0}(0.2), n_{1}(0.4), n_{2}(0.4)\right\} \\
s_{2}(0.3)\left\{n_{2}(0.4), n_{3}(0.6)\right\} \\
s_{3}(0.4)\left\{n_{2}(0.5), n_{3}(0.5)\right\}\end{array}$ & $\left.\begin{array}{c}s_{0}(0.2)\left\{n_{0}(0.5), n_{1}(0.5)\right\} \\
s_{1}(0.3)\left\{n_{0}(0.25), n_{1}(0.25), n_{2}(0.5)\right\} \\
s_{2}(0.3)\left\{n_{1}(0.375), n_{2}(0.25), n_{3}(0.375)\right\} \\
s_{3}(0.2)\left\{n_{0}(0.1), n_{1}(0.3), n_{2}(0.3), n_{3}(0.3)\right\}\end{array}\right\}$ & $\left\{\begin{array}{c}s_{0}(0.2)\left\{n_{0}(0.2), n_{1}(0.4), n_{2}(0.4)\right\} \\
s_{1}(0.2)\left\{n_{1}(0.5), n_{2}(0.5)\right\} \\
s_{2}(0.3)\left\{n_{2}(0.4), n_{3}(0.6)\right\} \\
s_{3}(0.3)\left\{n_{1}(0.2), n_{2}(0.4), n_{3}(0.4)\right\}\end{array}\right\}$ \\
\hline $\mathrm{NPN}^{-}$ & $\begin{array}{c}s_{0}(0.5)\left\{n_{2}(1)\right\} \\
s_{1}(0.2)\left\{n_{1}(0.4), n_{2}(0.6)\right\} \\
s_{2}(0.2)\left\{n_{1}(0.4), n_{2}(0.4), n_{3}(0.2)\right\} \\
s_{3}(0.1)\left\{n_{2}(0.2), n_{3}(0.8)\right\}\end{array}$ & $\left.\begin{array}{c}s_{0}(0.4)\left\{n_{0}(0.1), n_{1}(0.2), n_{2}(0.2), n_{3}(0.5)\right\} \\
s_{1}(0.4)\left\{n_{1}(0.6), n_{2}(0.4)\right\} \\
s_{2}(0.1)\left\{n_{2}(0.2), n_{3}(0.8)\right\} \\
s_{3}(0.1)\left\{n_{2}(0.4), n_{3}(0.6)\right\}\end{array}\right\}$ & $\left\{\begin{array}{c}s_{0}(0.4)\left\{n_{0}(0.1), n_{1}(0.3), n_{2}(0.6)\right\} \\
s_{1}(0.2)\left\{n_{1}(0.3), n_{2}(0.4), n_{3}(0.3)\right\} \\
s_{2}(0.2)\left\{n_{2}(0.4), n_{3}(0.6)\right\} \\
s_{3}(0.2)\left\{n_{2}(0.7), n_{3}(0.3)\right\}\end{array}\right\}$ \\
\hline
\end{tabular}

$$
\begin{aligned}
\max & D(\omega)=\sum_{i=1}^{4} D_{i}(\omega) \\
& =\sum_{j=1}^{3} \sum_{i=1}^{4} \sum_{k=1}^{4}\left(\frac{\omega_{j}}{4 \times 5} \sum_{k=1}^{4} \sum_{l=1}^{5}\left(\frac{\left(\left(\left|\mathrm{OL}_{i j}^{(k)}-\mathrm{OL}_{k j}^{(k)}\right| / 4+1\right)+\left|p_{i j}^{(k)}-p_{k j}^{(k)}\right|+\left(\left|I L_{i j}^{(l)}-I L_{k j}^{(l)}\right| / 5+1\right)+\left|v_{i j}^{(l)}-v_{k j}^{(l)}\right|\right)}{4}\right)^{\lambda}\right)^{1 / \lambda}
\end{aligned}
$$

s.t. $\quad 0.2 \leq \omega_{1} \leq 0.4,0.3 \leq \omega_{2} \leq 0.5,0.2 \leq \omega_{3} \leq 0.4,0.1 \omega_{2} \leq \omega_{3}$,

$$
\sum_{j=1}^{3} \omega_{j}=1, \omega_{j} \geq 0, j=1,2,3 .
$$

Suppose that the parameter $\lambda=1$, and the model is simplified as

$$
\begin{array}{ll}
\max & D(\omega)=0.45 \omega_{1}+0.5563 \omega_{2}+0.4525 \omega_{3} \\
\text { s.t. } & 0.2 \leq \omega_{1} \leq 0.4,0.3 \leq \omega_{2} \leq 0.5,0.2 \leq \omega_{3} \leq 0.4,0.1 \omega_{2} \leq \omega_{3}, \\
& \sum_{j=1}^{3} \omega_{j}=1, \omega_{j} \geq 0, j=1,2,3 .
\end{array}
$$

The weight vector can be obtained by Lingo 11, and the result is $\omega=(0.2,0.5,0.3)^{T}$.

Next, the proposed extended TOPSIS method is used to evaluate the river health, and the following steps are as follows:

Step 1. Considering that attributes are all benefit-type, the PIS NPN ${ }^{+}$and the NIS NPN ${ }^{-}$of the objects are listed in Table 3 according to Table 2.
Step 2. According to equations (15) and (16), the deviation $d\left(x_{i}, \mathrm{NPN}^{+}\right)$and $d\left(x_{i}, \mathrm{NPN}^{-}\right)$can be calculated as follows:

$$
\begin{aligned}
& d\left(x_{i}, \mathrm{NPN}^{+}\right)=(0.0785,0.0452,0.0800,0.0516), \\
& d\left(x_{i}, \mathrm{NPN}^{-}\right)=(0.1224,0.0257,0.0538,0.0727) .
\end{aligned}
$$

Step 3. Get $d_{\text {min }}\left(x_{i}, \mathrm{NPN}^{+}\right)=0.0452$ and $d_{\max }\left(x_{i}\right.$, $\left.\mathrm{NPN}^{-}\right)=0.1224$.

Step 4. According to equation (19), the inner weight $\varepsilon_{i}\left(x_{i}\right)$ of the object can be calculated as follows:

$$
\varepsilon_{i}\left(x_{i}\right)=(0.3430,0.1556,0.2833,0.2182)^{T} .
$$

Step 5. According to equation (20), the innerlayer score $\mathrm{IZ}_{i}$ of the object can be calculated as follows: 
$I Z_{1}=\left(\begin{array}{cccc}0.1253 & 0.2505 & 0.3494 & 0.0567 \\ 0 & 0 & 0.2680 & 0.3694 \\ 0.1444 & 0 & 0.1133 & 0.0850 \\ 0.2844 & 0.2991 & 0 & 0 \\ 0.0467 & 0.0878 & 0.6474 & 0\end{array}\right)$,
$I_{2}=\left(\begin{array}{cccc}0.0778 & 0.2477 & 0.4563 & 0 \\ 0 & 0.0389 & 0.2894 & 0.4535 \\ 0 & 0 & 0 & 0.1955 \\ 0.2327 & 0.3536 & 0 & 0.0156 \\ 0.0467 & 0.1719 & 0.5477 & 0\end{array}\right)$,

$\mathrm{IZ}_{3}=\left(\begin{array}{cccc}0.1725 & 0.3305 & 0.2011 & 0.0778 \\ 0 & 0.0686 & 0.3155 & 0.3127 \\ 0.0850 & 0 & 0 & 0 \\ 0.2816 & 0.5002 & 0 & 0 \\ 0 & 0.4320 & 0.3498 & 0\end{array}\right)$

$\mathrm{IZ}_{4}=\left(\begin{array}{cccc}0.0722 & 0.1755 & 0.5341 & 0 \\ 0 & 0 & 0.3909 & 0.3909 \\ 0 & 0 & 0 & 0.0622 \\ 0.3127 & 0.4069 & 0 & 0 \\ 0.1033 & 0.3594 & 0.3191 & 0\end{array}\right)$.

Step 6. According to Definition 2, the whole score $F\left(\mathrm{NPN}_{i}\right)$ of the object are

$$
F\left(\mathrm{NPN}_{i}\right)=(0.8071,0.7602,0.7227,0.7653)
$$

Step 7. Rank the objects by comparison rule, that is, $x_{1}>x_{4}>x_{2}>x_{3}$, and the best object is the Yangtze River.

5.3. Comparative Analysis and Discussion. In order to verify the superiority of the proposed method, we make some comparative analysis based on simulation experiments by MATLAB from three aspects: (1) the impact for the results without weight optimization; (2) the impact for the results under other uncertain environments; (3) the impact for the results using other decision-making methods.

5.3.1. The Impact without Weight Optimization. Suppose that the attribute weights satisfy several cases, such as uniform distribution, increase progressively, decrease progressively, and irregular situation. With different attribute weights, the whole scores of the objects and the rankings are shown in Table 4.

As we can see, different attribute weights have effect on the whole scores of the objects, and the rankings are also a little different. Although the best object and the worst object are $x_{1}$ and $x_{3}$, respectively, the rank of $x_{2}$ and $x_{4}$ are different because of the various attribute weights. Therefore, it can be concluded that when the numbers of objects and attributes are large, it is necessary to make full use of information to optimize the weight. Because various attribute weights may lead to different ranking results, it is also one of the most important factors to obtain a rational result.

In the following, we further analyze the relationship between the attribute weights and the whole scores of objects. We generate 1000 sets of attribute weights randomly based on MATLAB and apply to the same case, and the whole scores of each object can be shown in Figure 2 .

In general, the range of the whole scores is from 0.5 to 0.95. In Figure 2(a), the whole scores of $x_{1}$ are almost the highest, while the whole scores of $x_{3}$ are almost the lowest. And the whole scores of $x_{2}$ and $x_{4}$ are larger and smaller alternatively. In Figure 2(b), we can see the trend clearly with various attribute weights. Specifically, the maximum values of the whole scores of four objectives are 0.9384 , $0.8950,0.8942$, and 0.9167 , respectively. The minimum values of the whole scores of four objectives are 0.6623 , $0.6234,0.5064$, and 0.5857 , respectively. Therefore, the attribute weights can affect the whole scores about $20 \%$, and it is meaningful to determine the weights rationally and scientifically.

5.3.2. The Impact under Other Uncertain Environments. Next, we study the case using different linguistic evaluation methods. In Section 5.2, experts use the NPNLTSs to express the evaluation information considering outer and inner linguistic information. Then, hesitant fuzzy linguistic term sets (HFLTSs) [8] and probabilistic linguistic term sets (PLTSs) [9] are used to assess evaluation information of the objects with respect to the attributes, respectively. Table 5 and 6 list the evaluation information with HFLTSs and PLTSs, respectively.

Similarly, we use TOPSIS methods with HFLTSs and PLTSs to deal with the case, and the rankings are listed in Table 7.

The ranking results show that $x_{1}$ is the best object by TOPSIS methods with PLTSs and NPNLTSs, while $x_{4}$ is the best object by TOPSIS methods with HFLTSs, and the 
TABLE 4: The whole scores of the objects and the rankings with different attribute weights.

\begin{tabular}{llllll}
\hline$\omega$ & $F\left(x_{1}\right)$ & $F\left(x_{2}\right)$ & $F\left(x_{3}\right)$ & $F\left(x_{4}\right)$ & Rankings \\
\hline$\omega=(1 / 3,1 / 3,1 / 3)^{T}$ & 0.7444 & 0.7008 & 0.6388 & 0.6921 & $x_{1}>x_{2}>x_{4}>x_{3}$ \\
$\omega=(0.1,0.3,0.6)^{T}$ & 0.7833 & 0.7309 & 0.6819 & 0.7318 & $x_{1}>x_{4}>x_{2}>x_{3}$ \\
$\omega=(0.6,0.3,0.1)^{T}$ & 0.6963 & 0.6602 & 0.5803 & 0.6396 & $x_{1}>x_{4}>x_{2}>x_{3}$ \\
$\omega=(0.4,0.5,0.1)^{T}$ & 0.7656 & 0.7248 & 0.6738 & 0.7207 & $x_{1}>x_{2}>x_{4}>x_{3}$ \\
$\omega=(0.2,0.5,0.3)^{T}$ & 0.8071 & 0.7602 & 0.7227 & 0.7653 & $x_{1}>x_{4}>x_{2}>x_{3}$ \\
\hline
\end{tabular}

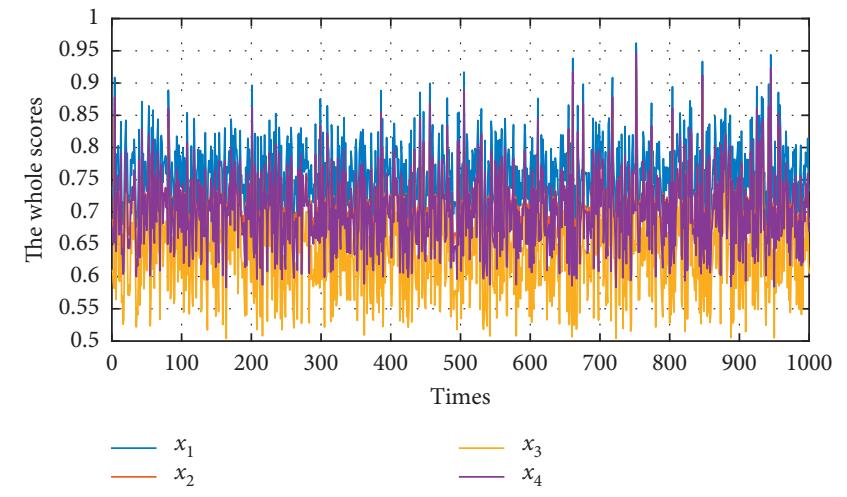

(a)

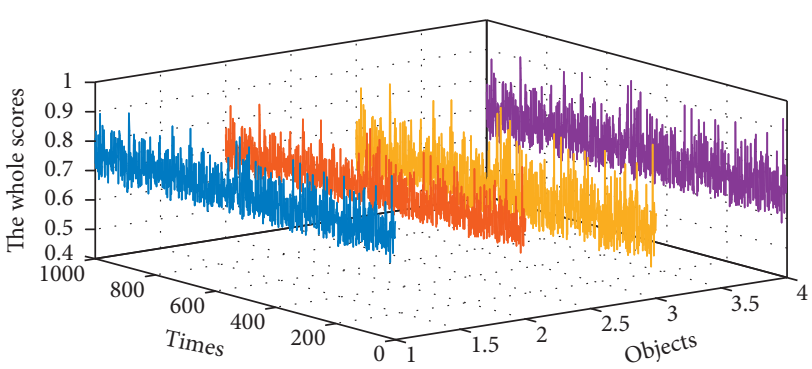

(b)

Figure 2: The whole scores of each object with 1000 sets of attribute weights: (a) two-dimensional diagram; (b) three-dimensional diagram.

TABLE 5: The evaluation information with HFLTSs.

\begin{tabular}{lccc}
\hline & $c_{1}$ & $c_{2}$ & $c_{3}$ \\
\hline$x_{1}$ & $\left\{s_{2}, s_{3}\right\}$ & $\left\{s_{1}, s_{2}, s_{3}\right\}$ & $\left\{s_{0}, s_{1}, s_{2}, s_{3}\right\}$ \\
$x_{2}$ & $\left\{s_{2}\right\}$ & $\left\{s_{1}, s_{2}, s_{3}\right\}$ & $\left\{s_{2}, s_{3}\right\}$ \\
$x_{3}$ & $\left\{s_{2}, s_{3}\right\}$ & $\left\{s_{0}, s_{1}, s_{2}, s_{3}\right\}$ & $\left\{s_{0}, s_{1}, s_{2}\right\}$ \\
$x_{4}$ & $\left\{s_{2}, s_{3}\right\}$ & $\left\{s_{1}, s_{2}\right\}$ & $\left\{s_{1}, s_{2}, s_{3}\right\}$ \\
\hline
\end{tabular}

TABLE 6: The evaluation information with PLTSs.

\begin{tabular}{cccc}
\hline & $c_{1}$ & $c_{2}$ & $c_{3}$ \\
\hline$x_{1}$ & $\left\{s_{0}(0.2), s_{1}(0.2), s_{2}(0.4), s_{3}(0.2)\right\}$ & $\left\{s_{0}(0.2), s_{1}(0.5), s_{2}(0.1), s_{3}(0.2)\right\}$ & $\left\{s_{0}(0.25), s_{1}(0.25), s_{2}(0.25), s_{3}(0.25)\right\}$ \\
$x_{2}$ & $\left\{s_{0}(0.5), s_{1}(0.2), s_{2}(0.2), s_{3}(0.1)\right\}$ & $\left\{s_{0}(0.2), s_{1}(0.3), s_{2}(0.3), s_{3}(0.2)\right\}$ & $\left\{s_{0}(0.3), s_{1}(0.2), s_{2}(0.3), s_{3}(0.2)\right\}$ \\
$x_{3}$ & $\left\{s_{0}(0.1), s_{1}(0.2), s_{2}(0.3), s_{3}(0.4)\right\}$ & $\left\{s_{0}(0.4), s_{1}(0.4), s_{2}(0.1), s_{3}(0.1)\right\}$ & $\left\{s_{0}(0.4), s_{1}(0.2), s_{2}(0.2), s_{3}(0.2)\right\}$ \\
$x_{4}$ & $\left\{s_{0}(0.2), s_{1}(0.2), s_{2}(0.2), s_{3}(0.4)\right\}$ & $\left\{s_{0}(0.2), s_{1}(0.4), s_{2}(0.2), s_{3}(0.2)\right\}$ & $\left\{s_{0}(0.2), s_{1}(0.2), s_{2}(0.3), s_{3}(0.3)\right\}$ \\
\hline
\end{tabular}

TABLE 7: Rankings with different linguistic models.

\begin{tabular}{lc}
\hline Methods & Rankings \\
\hline The TOPSIS method with HFLTSs [40] & $x_{4}>x_{1}>x_{3}>x_{2}$ \\
The TOPSIS method with PLTSs [9] & $x_{1}>x_{2}>x_{4}>x_{3}$ \\
The proposed method & $x_{1}>x_{4}>x_{2}>x_{3}$ \\
\hline
\end{tabular}

rankings are different by TOPSIS methods with three various linguistic models. The reason may be that HFLTSs do not consider the weight of linguistic terms, and PLTSs cannot better reflect information comprehensively according to Tables 5 and 6 . Therefore, the results by the decision method with NPNLTSs are more reasonable and reliable.
TABLE 8: Rankings by four decision-making methods.

\begin{tabular}{lc}
\hline Methods & \multicolumn{1}{c}{ Rankings } \\
\hline The aggregation method [18] & $x_{1}>x_{4}>x_{3}>x_{2}$ \\
The VIKOR method [41] & $x_{1}>x_{4}>x_{2}>x_{3}$ \\
The ELECTRE method [42] & $x_{1}>x_{2}>x_{4}>x_{3}$ \\
The proposed method & $x_{1}>x_{4}>x_{2}>x_{3}$ \\
\hline
\end{tabular}

5.3.3. The Impact Using Other Decision-Making Methods. Finally, we make analysis to compare the proposed method with other decision-making methods with NPNLTSs, which are aggregation method [18], VIKOR method [41], and ELECTRE method [42]. Suppose that the attribute weights are $\omega=(0.2,0.5,0.3)^{T}$, four methods above are used to deal 


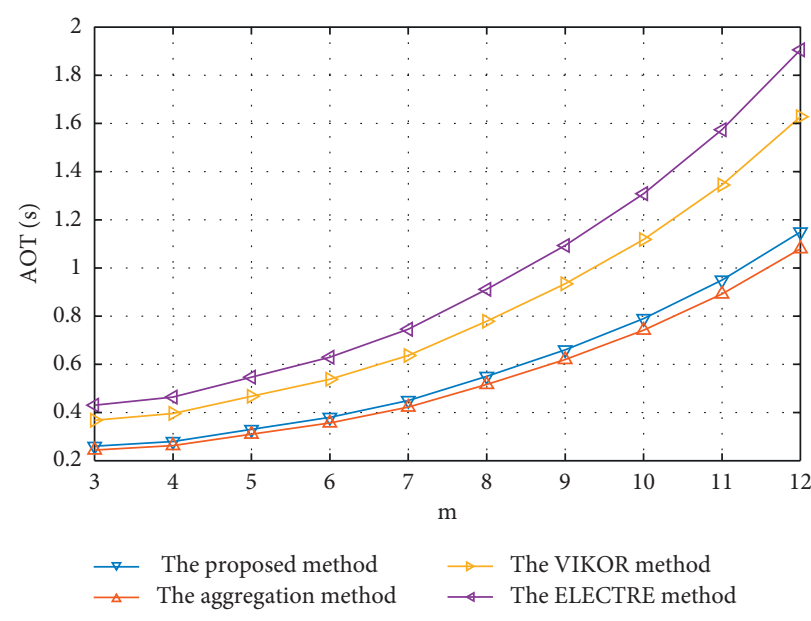

(a)

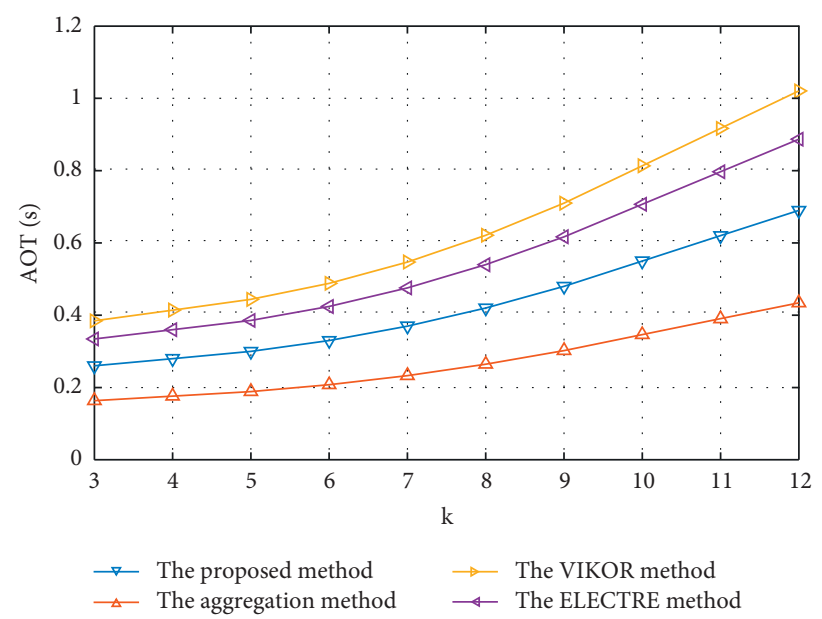

(b)

FIgURE 3: The average operation time by four decision-making methods: (a) $m$ is from 3 to 12 with $k=3$; (b) $k$ is from 3 to 12 with $m=3$.

with the same case, and the ranking results are listed in Table 8.

As we can see from Table 8 , ranking results by four decision-making methods are a little different. Specifically, all the best objects are $x_{1}$, and the rankings are the same by the proposed method and the VIKOR method. To some extent, the proposed TOPSIS method is reliable.

In order to further study the effectiveness of the proposed method, we make simulation experiments to analyze the average operation time (AOT) by four decision-making methods. Let $m$ and $k$ be the number of objects and attributes, respectively. When $m$ and $k$ are from 3 to 12 after 1000 simulation times, the AOTs by four decision-making methods are shown in Figure 3.

When $m$ and $k$ are from 3 to 12 , AOTs with four decision-making methods are all gradually increasing, and there are apparent differences by various methods. In Figure 3(a), the aggregation method takes the minimum AOT, and the ELECTRE method takes the maximum AOT. The AOT of the proposed method is little more than the aggregation method. In Figure 3(b), the minimum AOT also belongs to the aggregation method, while the maximum AOT belongs to the ELECTRE method. The proposed method also takes more time than the aggregation method. In addition, increasing the number of objects would take more time than increasing the number of attributes. Therefore, the proposed method is effective without taking too much time, and the results by the proposed method are also reliable.

\section{Conclusions}

In the complex environment, nested probabilistic-numerical linguistic term sets (NPNLTSs) are useful and flexible tools to express qualitative and quantitative information. Considering that attribute weight information is often incomplete and uncertain in decision-making problems. In this paper, we have established an optimization model with NPNLTSs based on distance measures to obtain the attribute weight.
Combined with the TOPSIS method and NPNLTSs, we have proposed an optimization-based TOPSIS method to deal with complex and uncertain decision-making problems, and have developed the corresponding algorithm. A case study about the river health assessment has been presented to show the effectiveness and practicability of the proposed method. In addition, we have made comparative analysis from three aspects including the impact for the results without weight optimization, the impact for the results under other uncertain environments, and the impact for the results using other decision-making methods. After discussions, the optimization-based TOPSIS method proposed in this paper shows effective and reliable, and the results make a technically sound contribution to the decision-making field.

In the future, some interesting topics about decisionmaking methods with NPNLTSs will be further studied. For example, the decision-making methods based on preference relation can be investigated with incomplete information. Moreover, we will study the situation where attribute weight and evaluation information are both incomplete and establish a rational decision-making method.

\section{Data Availability}

All experimental data and calculated data that support the findings of this study are available from the corresponding author upon reasonable request.

\section{Conflicts of Interest}

The authors declare that there are no conflicts of interest regarding the publication of this paper.

\section{Acknowledgments}

This work was supported by the grants for overseas returnees from Sichuan Provincial Human Resources and Social Security Department. 


\section{References}

[1] I. Deli and Y. Şubaş, "A ranking method of single valued neutrosophic numbers and its applications to multi-attribute decision making problems," International Journal of Machine Learning and Cybernetics, vol. 8, no. 4, pp. 1309-1322, 2017.

[2] İ. Deli, "Some operators with IVGSVTrN-numbers and their applications to multiple criteria group decision making," Neutrosophic Sets and Systems, vol. 25, pp. 33-53, 2019.

[3] L. A. Zadeh, "The concept of a linguistic variable and its application to approximate reasoning-I," Information Sciences, vol. 8, no. 3, pp. 199-249, 1975.

[4] I. B. Turksen, "Type 2 representation and reasoning for CWW," Fuzzy Sets Systems, vol. 127, no. 1, pp. 17-36, 2002.

[5] J. H. Wang and J. Hao, "A new version of 2-tuple fuzzy linguistic representation model for computing with words," IEEE Transactions on Fuzzy Systems, vol. 14, no. 3, pp. 435445, 2006.

[6] Y. Dong, Y. Xu, and S. Yu, "Computing the numerical scale of the linguistic term set for the 2-tuple fuzzy linguistic representation model," IEEE Transactions on Fuzzy Systems, vol. 17, no. 6, pp. 1366-1378, 2009.

[7] Z. Wu and J. Xu, "Possibility distribution-based approach for MAGDM with hesitant fuzzy linguistic information," IEEE Transactions on Cybernetics, vol. 46, no. 3, pp. 694-705, 2016.

[8] R. M. Rodriguez, L. Martinez, and F. Herrera, "Hesitant Fuzzy linguistic term sets for decision making," IEEE Transactions on Fuzzy Systems, vol. 20, no. 1, pp. 109-119, 2012.

[9] Q. Pang, H. Wang, and Z. Xu, "Probabilistic linguistic term sets in multi-attribute group decision making," Information Sciences, vol. 369, pp. 128-143, 2016.

[10] C. Wei, N. Zhao, and X. Tang, "Operators and comparisons of hesitant fuzzy linguistic term sets," IEEE Transactions on Fuzzy Systems, vol. 22, no. 3, pp. 575-585, 2014.

[11] Z. Tao, H. Chen, L. Zhou, and J. Liu, "On new operational laws of 2-tuple linguistic information using Archimedean t-norm and s-norm," Knowledge-Based Systems, vol. 66, pp. 156-165, 2014.

[12] X. Gou and Z. Xu, "Novel basic operational laws for linguistic terms, hesitant fuzzy linguistic term sets and probabilistic linguistic term sets," Information Sciences, vol. 372, no. 1, pp. 407-427, 2016.

[13] J. L. García-Lapresta and D. Pérez-Román, "Consensus-based clustering under hesitant qualitative assessments," Fuzzy Sets and Systems, vol. 292, pp. 261-273, 2016.

[14] H. Liao, Z. Xu, and X.-J. Zeng, "Distance and similarity measures for hesitant fuzzy linguistic term sets and their application in multi-criteria decision making," Information Sciences, vol. 271, pp. 125-142, 2014.

[15] X. Chen, H. Liang, Y. Gao, and W. Xu, "A method based on the disappointment almost stochastic dominance degree for the multi-attribute decision making with linguistic distributions," Information Fusion, vol. 54, pp. 10-20, 2020.

[16] J. Xiao, X. Wang, and H. Zhang, "Managing personalized individual semantics and consensus in linguistic distribution large-scale group decision making," Information Fusion, vol. 53, pp. 20-34, 2020.

[17] P. Liu and Y. Li, "An extended MULTIMOORA method for probabilistic linguistic multi-criteria group decision-making based on prospect theory," Computers \& Industrial Engineering, vol. 136, pp. 528-545, 2019.

[18] X. Wang, Z. Xu, and X. Gou, "Nested probabilistic-numerical linguistic term sets in two-stage multi-attribute group decision making," Applied Intelligence, vol. 49, no. 7, pp. 2582-2602, 2019.

[19] X. Wang, Z. Xu, X. Gou, and M. Xu, "Distance and similarity measures for nested probabilistic-numerical linguistic term sets applied to evaluation of medical treatment," International Journal of Fuzzy Systems, vol. 21, no. 5, pp. 1306-1329, 2019.

[20] C. Yue, "Entropy-based weights on decision makers in group decision-making setting with hybrid preference representations," Applied Soft Computing, vol. 60, pp. 737-749, 2017.

[21] Y. Chen, J. Yu, and S. Khan, "The spatial framework for weight sensitivity analysis in AHP-based multi-criteria decision making," Environmental Modelling \& Software, vol. 48, pp. 129-140, 2013.

[22] H. R. Zhao and S. Guo, "Risk evaluation on UHV power transmission construction project based on AHP and FCE method," Mathematical Problems in Engineering, vol. 2014, Article ID 687568, 14 pages, 2014.

[23] X. Zhang, Z. Xu, and H. Wang, "Heterogeneous multiple criteria group decision making with incomplete weight information: a deviation modeling approach," Information Fusion, vol. 25, pp. 49-62, 2015.

[24] D.-F. Li and S.-P. Wan, "Fuzzy linear programming approach to multiattribute decision making with multiple types of attribute values and incomplete weight information," Applied Soft Computing, vol. 13, no. 11, pp. 4333-4348, 2013.

[25] H. K. Jong and S. A. Byeong, "Extended VIKOR method using incomplete criteria weights," Expert Systems with Applications, vol. 126, no. 15, pp. 124-132, 2019.

[26] W. Song and J. Zhu, "Three-reference-point decision-making method with incomplete weight information considering independent and interactive characteristics," Information Sciences, vol. 503, pp. 148-168, 2019.

[27] Z. Zhang and C. Guo, "A method for multi-granularity uncertain linguistic group decision making with incomplete weight information," Knowledge-based Systems, vol. 26, pp. 111-119, 2012.

[28] İ. Deli, "A novel defuzzification method of SV-trapezoidal neutrosophic numbers and multi-attribute decision making: a comparative analysis," Soft Computing, vol. 23, no. 23, pp. 12529-12545, 2019.

[29] A. G. Balter and A. Pelsser, "Pricing and hedging in incomplete markets with model uncertainty," European Journal of Operational Research, vol. 282, no. 3, pp. 911-925, 2020.

[30] A. Rodríguez-Díaz, B. Adenso-Díaz, and P. L. GonzálezTorre, "Minimizing deviation from scheduled times in a single mixed-operation runway," Computers \& Operations Research, vol. 78, pp. 193-202, 2017.

[31] I. Deli and Y. Şubaş, "Some weighted geometric operators with SVTrN-numbers and their application to multi-criteria decision making problems," Journal of Intelligent \& Fuzzy Systems, vol. 32, no. 1, pp. 291-301, 2017.

[32] M. M. Salih, B. B. Zaidan, A. A. Zaidan, and M. A. Ahmed, "Survey on fuzzy TOPSIS state-of-the-art between 2007 and 2017," Computers \& Operations Research, vol. 104, pp. 207227, 2019.

[33] P. Baranitharan, K. Ramesh, and R. Sakthivel, "Multi-attribute decision-making approach for Aegle marmelos pyrolysis process using TOPSIS and Grey Relational Analysis: assessment of engine emissions through novel Infrared thermography," Journal of Cleaner Production, vol. 234, pp. 315-328, 2019.

[34] P. K. Kwok and H. Y. K. Lau, "Hotel selection using a modified TOPSIS-based decision support algorithm," Decision Support Systems, vol. 120, pp. 95-105, 2019. 
[35] P. Chen, "Effects of normalization on the entropy-based TOPSIS method," Expert Systems with Applications, vol. 136, no. 1, pp. 33-41, 2019.

[36] R. Micale, C. M. La Fata, and G. La Scalia, "A combined interval-valued ELECTRE TRI and TOPSIS approach for solving the storage location assignment problem," Computers \& Industrial Engineering, vol. 135, pp. 199-210, 2019.

[37] M. Abdel-Basset, M. Saleh, A. Gamal, and F. Smarandache, "An approach of TOPSIS technique for developing supplier selection with group decision making under type-2 neutrosophic number," Applied Soft Computing, vol. 77, pp. 438-452, 2019.

[38] K. S. Park, K. S. Lee, Y. S. Eum, and K. Park, "Extended methods for identifying dominance and potential optimality in multi-criteria analysis with imprecise informaiton," European Journal of Operational Research, vol. 134, no. 3, pp. 557-563, 2001.

[39] Z. Xu and M. Xia, "On distance and correlation measures of hesitant fuzzy information," International Journal of Intelligent Systems, vol. 26, no. 5, pp. 410-425, 2011.

[40] Z. Wu, J. Xu, X. Jiang, and L. Zhong, "Two MAGDM models based on hesitant fuzzy linguistic term sets with possibility distributions: VIKOR and TOPSIS," Information Sciences, vol. 473, pp. 101-120, 2019.

[41] S. M. Mousavi, B. Vahani, and S. S. Behzadi, "Designing a model of intuitionistic fuzzy VIKOR in multi-attribute group decision-making problems," Iranian Journal of Fuzzy Systems, vol. 13, no. 1, pp. 45-65, 2016.

[42] T.-Y. Chen, "An ELECTRE-based outranking method for multiple criteria group decision making using interval type-2 fuzzy sets," Information Sciences, vol. 263, pp. 1-21, 2014. 